\title{
A Community Hospital Report on the Incidence of Complications and Catheter Failures of Continuous Peripheral Nerve Block within 48 Hours Postoperatively
}

E BUCKLEY DNAP CRNA, M BURNS DNAP CRNA, B HEIDOTTEN MSN CRNA, C DOBSON BSN, B GOODMAN BSN PHELPS COUNTY REGIONAL MEDICAL CENTER, WEBSTER UNIVERSITY

\section{Background and Aims:}

Continuous peripheral nerve blocks are included in multiple ERAS protocols following major orthopedic surgery. Continuous peripheral nerve blocks provide non-opioid postoperative pain relief with varied success rates reported in the literature. The purpose of this study is to evaluate the incidence and complications within 48 hours postoperatively in a community hospital setting.

\begin{tabular}{|l|l|l|}
\hline & $\begin{array}{l}\text { Duration } \\
>48 \text { hours }\end{array}$ & $\begin{array}{l}\text { Duration } \\
<48 \text { hours }\end{array}$ \\
\hline Age & 54.0 & 55.7 \\
\hline BMI & 32.1 & 33.3 \\
\hline ASA & 2.3 & 2.6 \\
\hline Female Sex & 387 & 81 \\
\hline Male Sex & 307 & 54 \\
\hline
\end{tabular}

\section{Explanation of $<48$}

\section{Hour Duration}

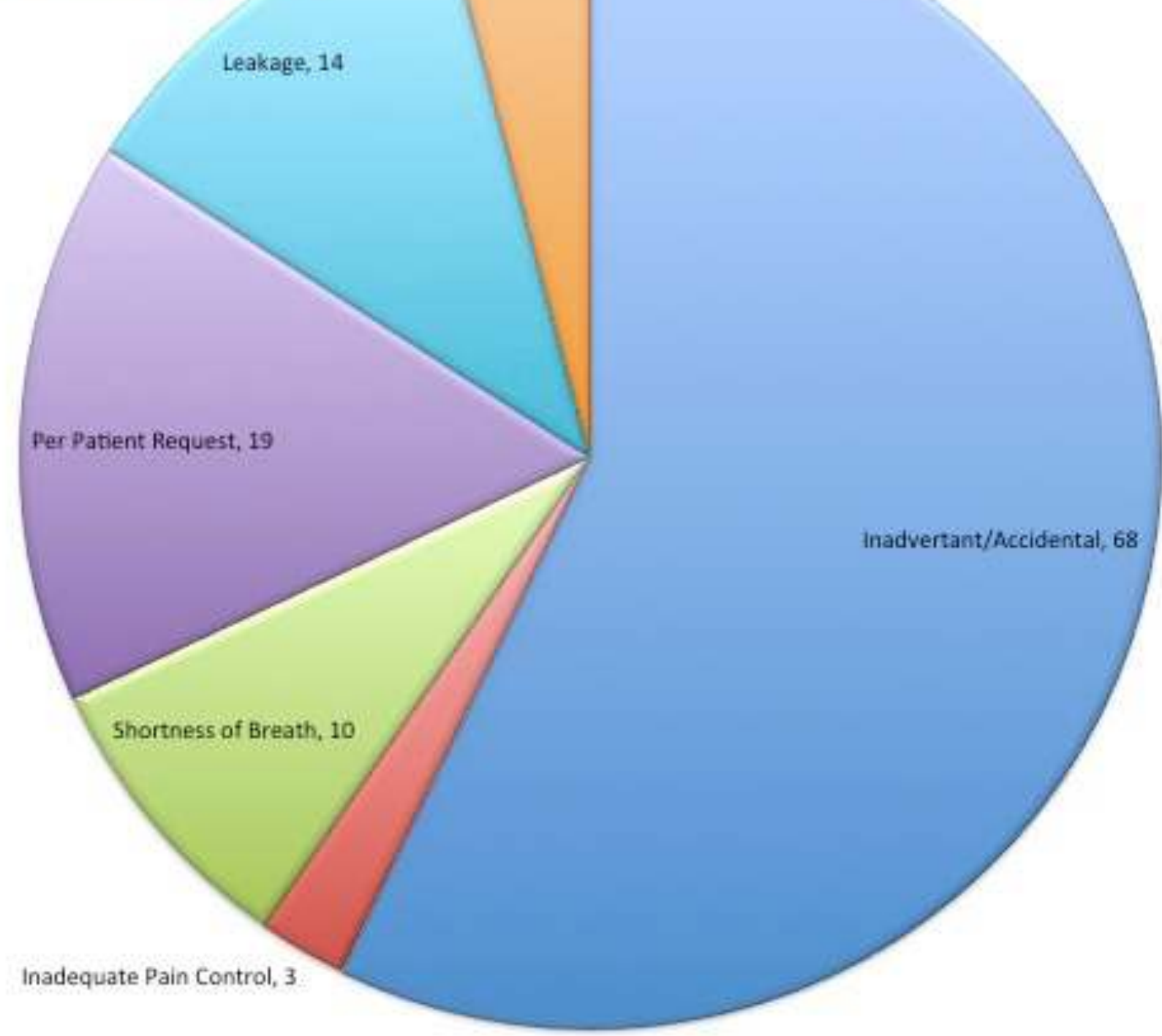

\section{Methods:}

IRB approval was obtained prior to performing a retrospective chart review of 806 continuous peripheral nerve blocks performed at a community hospital.

\begin{tabular}{|c|c|c|c|c|c|}
\hline & $\begin{array}{c}\text { Brachial } \\
\text { Plexus } \\
\text { Axillary }\end{array}$ & $\begin{array}{c}\text { Brachial } \\
\text { Plexus } \\
\text { Interscalene }\end{array}$ & $\begin{array}{c}\text { Brachial } \\
\text { Plexus } \\
\text { Supraclavicular }\end{array}$ & Femoral & Sciatic \\
\hline $\begin{array}{c}\text { Duration } \\
>48 \\
\text { hours }\end{array}$ & $85 \%$ & $88 \%$ & $87 \%$ & $78 \%$ & $84 \%$ \\
\hline $\begin{array}{c}\text { Duration } \\
<48 \\
\text { hours }\end{array}$ & $15 \%$ & $12 \%$ & $13 \%$ & $22 \%$ & $16 \%$ \\
\hline \hline
\end{tabular}

\section{Results:}

Upper extremity continuous nerve blocks remained in place for more than 48 hours at a greater rate than lower extremity nerve blocks. Continuous axillary nerve blocks remained in place at a rate of $85 \%$, interscalene $88 \%$, supraclavicular $87 \%$. Continuous femoral and sciatic nerve blocks remained in for greater than 48 hours $78 \%$ of the time.

\section{Conclusion:}

Continuous upper and lower extremity nerve blocks remain in place for greater than 48 hours an average of $84 \%$ of the time. This provides non opioid pain relief in conjunction with ERAS protocols with continued success for greater than 48 hours consistently. The most common cause of block removal (advertent or inadvertent) was accidental removal suggesting low rates of removal related to block complications. 